\title{
Synthesis and anti-bacteria activity of a Gemini cationic surfactant
}

\author{
Ren Chunyan \\ Department of Physical Education, Yulin University, Yulin 719000, China \\ 916490618@qq.com
}

Keywords: cationic surfactant, synthesis, critical micelle concentration, antibacterial activity

\begin{abstract}
As quaternary ammonium cationic surfactants are widely employed in pharmaceutical and cosmetic industries and in many applications, to develop new functional quaternary ammonium cationic surfactant, a new cationic surfactant was synthesized and characterized. The critical micelle concentration (CMC) and foamability and foam stability were evaluated, and the results showed that it reaches to $32.0 \mathrm{mN} / \mathrm{m}$ at the concentration of $1 \times 10^{-3} \mathrm{~mol} / \mathrm{L}$, the minimum surface tension was around $29.8 \mathrm{mN} / \mathrm{m}$ beyond $1 \times 10^{-2} \mathrm{~mol} / \mathrm{L}$. This compound was evaluated for their in vitro antimicrobial activity against six bacteria (S. aureus, S. epidermidis, M. luteus, E. coli, K. pneumoniae, A. fumigatus). It some anti-inflammatory activity against the tested bacteria and the inhibition is depending on the concentration.
\end{abstract}

\section{Introduction}

Gemini surfactants have two hydrophobic tails and two hydrophilic head groups connected through a linkage adjacent to the hydrophilic head groups in a molecule[1-3], which have attracted great attention from both industrial and academic fields [4-5]. They display greater propensity to form micelles and can efficiently reduce interface tension compared with their corresponding conventional single-chain surfactant counterparts, and the Gemini surfactants have been widely used in many fields [6-10].Quaternary ammonium cationic surfactants are widely employed in pharmaceutical and cosmetic industries and in many applications where they come into contact with the skin. Furthermore, these surfactants have been included in liposomes in order to obtain cationic liposomes which have the ability to transfer DNA into cells through fusion witch the cell membranes, or to form spontaneously complexes with DNA and RNA [12]. The cationic surfactants such as long chain substituted imidazolines and their quarternized imidazolinium salts are frequently used as fabric softeners, dispersants, anti-static agents, bleach activators, and emulsifiers not only because of their good performance but also for their mildness to eyes, skin and clothes and their biodegradability [13]. Despite having a positive charge, cationic surfactants have been known to have rather low solubility in water [14]. Increasing usage of cationic surfactants in industrial and household products has been causing environmental problems owing to poor biodegradability and thus much attention has been paid to develop environmental friendly, nontoxic and biodegradable cationic surfactants [14-18]. Also from an environment perspective, the most important property of cationic surfactants is that they strongly and rapidly adsorb to negatively charged surfaces of suspended solids and colloids. In view of this adsorption and antimicrobial behavior they demonstrate poor primary biodegradation and no evidence of ultimate biodegradation. In this work, a new Gemini cationic surfactant was synthesized and characterized, and the interfacial properties such as critical micelle concentration (CMC) and foam stability of the synthesized cationic surfactants were investigated.

\section{Experimental}

\section{Materials}

Malonic acid, isopropanol, N,N-dimethyldodecylamine and epichlorohydrin (99\%) were purchased from China National Pharmaceutical Group Corporation and were used without any further purification. Solvents such as ethyl ether, ethanol, and isopropanol were also used without further purification. Hydrochloric acid was purchased from Xi'an Chemical Company. Water used 
for sample preparation was ultrapure having been double distilled and passed through an ion exchange system.

Synthesis and characterization

A certain amount of malonic acid was added in to isopropanol, and then two equivalent of epichlorohydrin was added in dropwised under stirring at certain temperature. The mixture was stirred for $4 \mathrm{~h}$, and then a certain equivalent of $\mathrm{N}, \mathrm{N}$-dimethyldodecylamine was added and reacted for another $4 \mathrm{~h}$ under the same conditions. After the reaction finished, the solvent was evaporated, then resident was washed with diethyl ether for three times, recrystaled by ethanol, and dried under room temperature to produce the target compound (named as MDCA). The reaction is described as shown in Scheme 1. The product was identified by FT-IR spectrophotometer.

Surface tension measurements

The surface tension measurements of the prepared aqueous surfactant solutions were measured at $25^{\circ} \mathrm{C}$ using a Du Nuoy ring tensiometer with a platinum ring (Kruss K100, Germany). The platinum ring was cleaned several times by distilled water before each measurement to remove any residual deposit. Calibration was performed against a range of standard liquids to obtain an excellent agreement with the reference values. The surface tension was measured three times for each sample with a 40-min interval between each reading to ensure equilibrium data. The surface tension values were within an error less than or equal to $\pm 1 \mathrm{mN} / \mathrm{m}$.

The critical micelle concentration (CMC) was determined by measuring the conductivity of aqueous solutions of the compounds of increasing concentrations. The solutions were thermostated at $25{ }^{\circ} \mathrm{C}$ and maintained under agitation with a magnetic stirrer during the measurements. The CMC is given by the slope break in the conductivity vs. concentration curve.

Anti-inflammatory activity

The Anti-inflammatory activity was screened according to the reported method.

\section{Results and discussion}

\section{Chemistry}

During the synthesis of target molecule (MDCA), the malonic acid reacts with epichlorohydrin at the first step with the molar ratio of 1:2 by a typical substitution reaction. In the second step, $\mathrm{N}, \mathrm{N}$-dimethyldodecylamine quarterizated with two chloro primary carbon and produced the final quaternary ammonium Gemini surfactants with two hydroxyl groups. All the reaction process was summarized in Scheme 2. The synthesized cationic surfactants having two hydroxyl groups and two cations as well as two ester groups, and the counter ion is chloride. The specific bands likes $\mathrm{O}-\mathrm{H}$ stretching band (3415 cm-1), $\mathrm{sp}^{3} \mathrm{C}-\mathrm{H}$ stretching band $\left(2922 \mathrm{~cm}^{-1}, 2851 \mathrm{~cm}^{-1}\right), \mathrm{O}=\mathrm{O}$ stretching band $\left(1685 \mathrm{~cm}^{-1}\right), \mathrm{C}-\mathrm{H}$ bending band $\left(1482 \mathrm{~cm}^{-1}\right), \mathrm{C}-\mathrm{N}$ stretching band $\left(1121 \mathrm{~cm}^{-1}\right)$, and $\mathrm{C}-\mathrm{O}$ stretching band $\left(1102 \mathrm{~cm}^{-1}\right)$ could be able to determine through IR spectra.
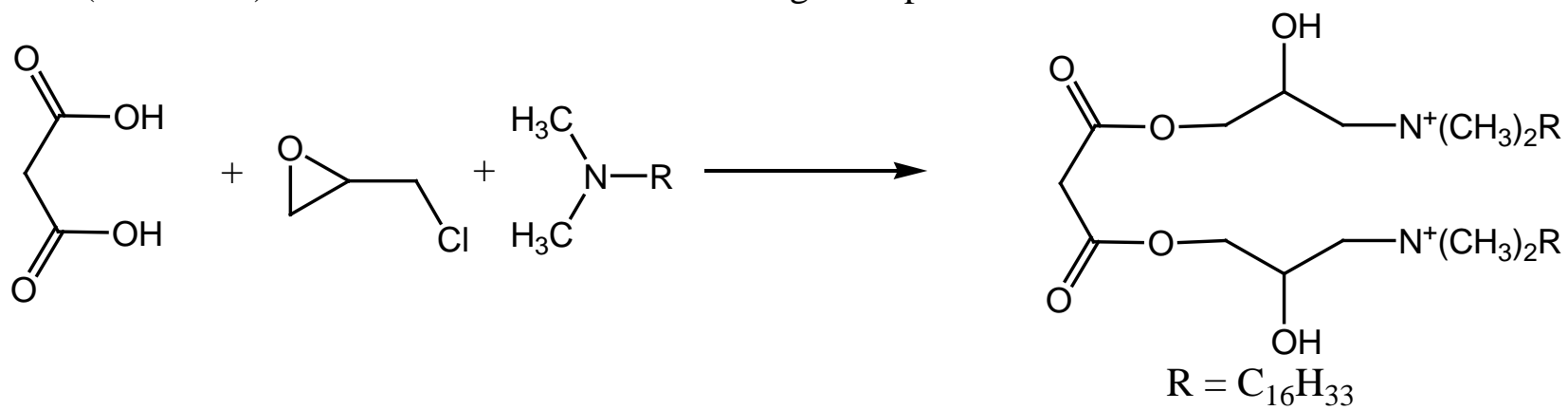

Scheme 1 The synthesis of new Gimini cationic surfactant (MDCA)

The conditions of in the second step were investigated including the temperature, reaction time, and molar ratio. The temperature was investigated at first with the reaction time of $4 \mathrm{~h}$, and molar ratio of malonic acid : epichlorohydrin : N,N-dimethyldodecylamine $=1: 2.2: 2.2$. During the reaction it has been found that the temperature play a important role in this reaction, low temperature leads to low yield, and it becomes ineffectively above $80{ }^{\circ} \mathrm{C}$. The yield reaches to $80 \%$ at $80{ }^{\circ} \mathrm{C}$, and at the 
boiling point of the solvent the yield reaches to $81 \%$. So the reaction temperature can be selected as $80{ }^{\circ} \mathrm{C}$.

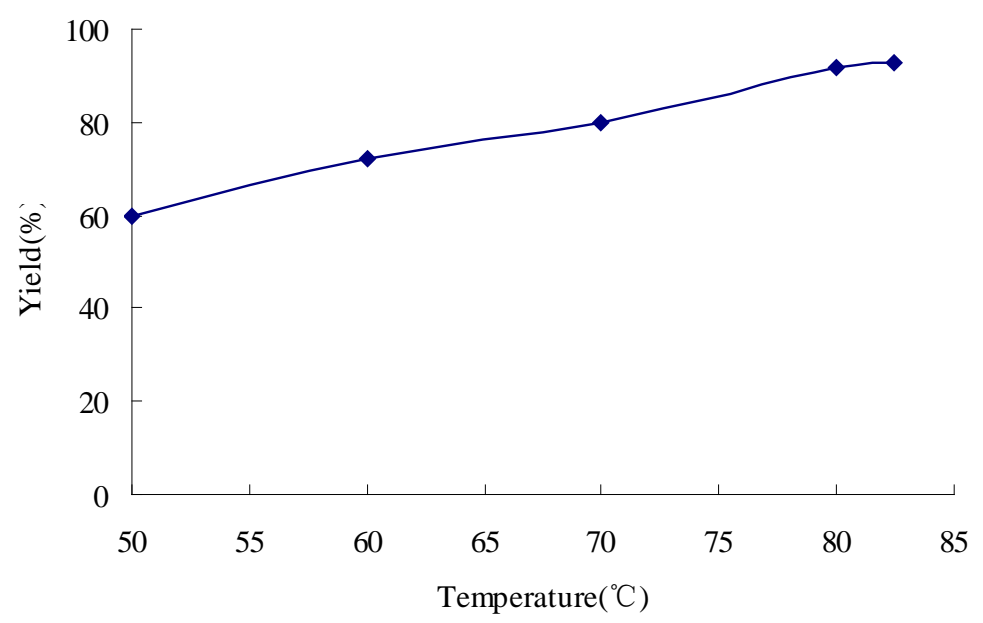

Figure 1 The effect of temperature on the yield of MDCA

\section{The Structure Characterization}

The stable conformation of the anionic part of MDCA was shown in Figure 2. The optimized geometries evidence that the nonpolar part, the two hexadecyl groups adopts a significantly linear conformation, which seems to result in a more efficient packing in the solid state, inducing a strong trend to crystallize that is, in this case, not compensated by the increase of hydrophilicity, and thus inducing a higher Krafft temperature. The hydrophilic part is strictly compensated by a poor trend to crystallize.

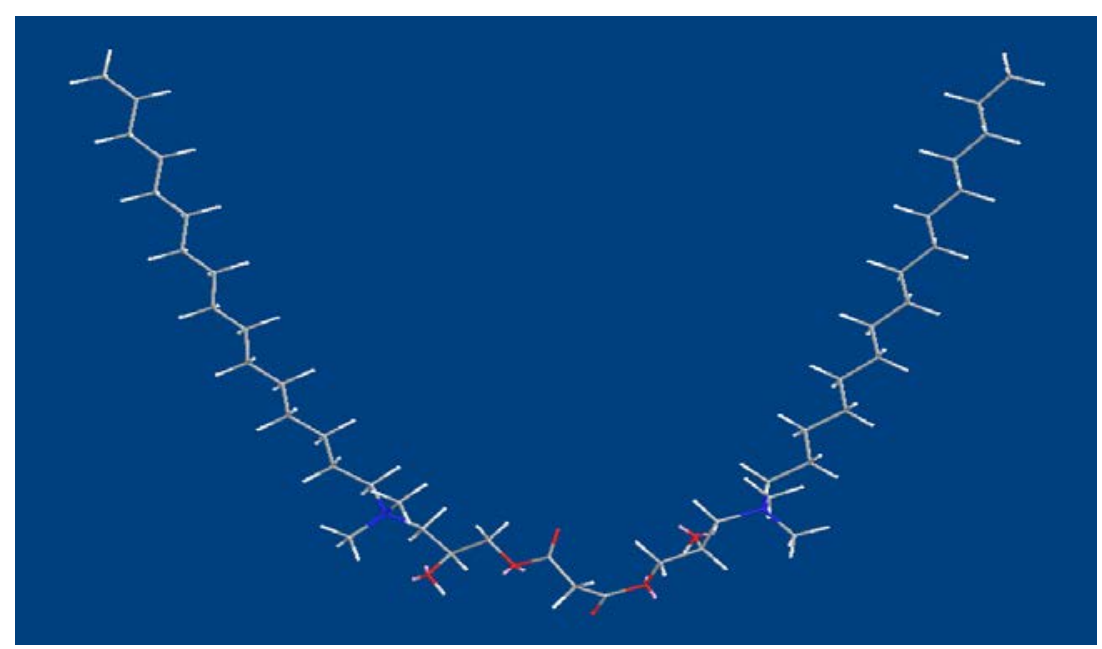

Figure 2 The stable conformation of MDCA

\section{Interfacial properties}

The CMC was determined by measuring the surface tension of the surfactant as a function of concentration. The CMC was taken as the concentration beyond which the surface tension of the aqueous solution does not decrease any more. Surface tension of aqueous surfactant solution was measured by a Du Nuoy ring tensiometer at $25^{\circ} \mathrm{C}$ and the results at $\mathrm{CMC}$ condition are summarized in Figure 3. As shown in Figure 3, the surface tension of aqueous surfactant solution has been found it reaches to $32.0 \mathrm{mN} / \mathrm{m}$ at the concentration of $1 \times 10^{-3} \mathrm{~mol} / \mathrm{L}$, the minimum surface tension was around $29.8 \mathrm{mN} / \mathrm{m}$ beyond $1 \times 10^{-2} \mathrm{~mol} / \mathrm{L}$. 


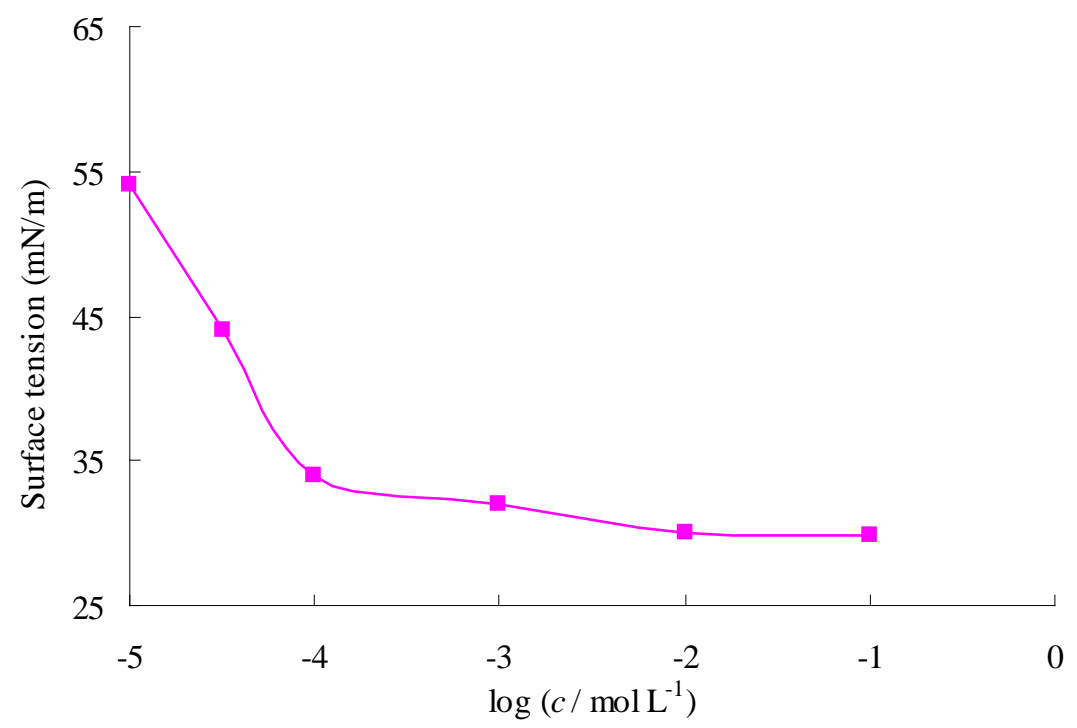

Figure 3 The surface intension of MDCA

\section{Anti-inflammatory activity}

In the daily sports and fitness, there will be some small accidents, such as sprains, contusions, bleeding, etc., especially when injury wound contacts with the ground infiltrating some bacteria. Young people are generally infected gram-positive bacteria, and the physical weak elderly are inclined to be infected with gram-negative bacteria. The most common infective bacteria are such gram-positive bacteria as Staphylococcus aureus, Streptococcus pneumoniae, Streptococcus pyogenes and such Gram-negative as Escherichia coli, Haemophilus influenzae. In vivo infection by pathogenic microorganisms will cause acute systemic infection, especially for the children, the elderly, immunocompromised or with chronic diseases, and without timely treatment there will be some complications and even sepsis or sepsis. In this work, we investigated the anti-inflammatory activity of the title compound under the concentration of $20 \mathrm{mg} / \mathrm{L}$ and $200 \mathrm{mg} / \mathrm{L}$. and the results were summarized in Table 1. From the results, it was found that the title compound shows some anti-inflammatory activity against the tested bacteria and the inhibition is depending on the concentration. The title compound are more active against $S$. aureus, $S$. epidermidis, and E. coli under both concentration with the inhibition effect more than $50 \%$ under $20 \mathrm{mg} / \mathrm{L}$ and the highest inhibition effect of $90.2 \%$ under $200 \mathrm{mg} / \mathrm{L}$ against $S$. epidermidis. But it is not so active against other three bacteria, M. luteus, K. pneumoniae, and A. fumigatus, with much lower inhibition effects.

Table 1 The anti-inflammatory activity of the title compound

\begin{tabular}{|c|c|c|c|c|c|c|}
\hline Bacteria & S. aureus & S. epidermidis & M. luteus & E. coli & K. pneumoniae & A. fumigatus \\
\hline $\begin{array}{c}\text { Inhibition effect /\% } \\
(20 \mathrm{mg} / \mathrm{L})\end{array}$ & 71.5 & 88.1 & 56.7 & 83.1 & 56.1 & 63.8 \\
\hline $\begin{array}{c}\text { Inhibition effect /\% } \\
(200 \mathrm{mg} / \mathrm{L})\end{array}$ & 82.5 & 90.2 & 68.9 & 86.4 & 45.9 & 69.5 \\
\hline
\end{tabular}

\section{Conclusion}

In this study, a new cationic surfactant was synthesized by the condensation reaction of malonic acid and epichlorohydrin followed by the quarternization with dimethyl amine. The reaction conditions were investigated, and the structure of the resulting products was elucidated by FT-IR. The critical micelle concentration of the aqueous surfactant solution has been found to increase with increasing the hydrophilicity of a surfactant, and the minimum surface tension was around 28.5 $\mathrm{mN} / \mathrm{m}$. It has been observed that the results for foam stability measurement are consistent with those of CMC. 


\section{Acknowledgements}

This work was financially supported by Scientific Research Program Funded by Shaanxi Provincial Education Department (12JK0589) and Grand Science and Technology Special Project of Yulin (2015cxy-07).

\section{References}

[1]A.S. Mohamed, M.Z. Mohamed, J. Surf. Deterg. 13 (2010) 159-165.

[2]T. Tatsumi, W. Zhang, T. Kida, Y. Nakatsuji, D. Ono, T. Takeda, I. Ikeda, J. Surf. Deterg. 3, (2000) 167-171.

[3]O. Kirk, F.D. Pedersen, C.C. Fuglsang, J. Surf. Deterg. 1 (1998) 37-42.

[4]P.E. Hellberg, J. Surf. Deterg. 5 (2002) 217-220.

[5]Z. Miao, J. Yang, L. Wang, Y. Liu, L. Zhang, X. Li, L. Peng, Mater. Lett. 62 (2008) 3450-3455.

[6]B.M. Lee, H.C. Kang, J.M. Park, J. Yoon, US Patent 6,392,064 (2002).

[7]E.K. Kang, B.M. Lee, H.A. Hwang, J.C. Lim, J. Ind. Eng. Chem. 17 (2011) 845-851.

[8]H.S. Kielman, P.H.F. Van Steen, Surface Active Agents, Society Chemical Industry, London, (1979).

[9]J.M. Park, H.C. Kim, B.M. Lee, D.P. Kim, J. Kor. Ind. Eng. Chem. 14 (2003) 249-253.

[10] C.A. Miller, P. Neogi, Interfacial Phenomena: Equilibrium and Dynamic Effects, Marcel Dekker Inc, New York (1985).

[11] D.W. Chung, J.C. Lim, Colloids Surf. A, 336 (2009) 35-39.

[12] K.P. Ananthapadmanabham, E.D. Goddard, P. Chandar, Colloid Surf. 44 (1990) 281-285.

[13] F.J. Mori, C. Lim, O.G. Raney, C.M. Elsik, C.A. Miller, Colloid Surf. 40 (1989) 323-329.

[14] J.C. Lim, J. Kor. Ind. Eng. Chem. 6 (1995) 610-615.

[15] F. Mori, J.C. Lim, C.A. Miller, Prog. Colloid Polym. Sci. 82 (1990) 114-120.

[16] H. Zhang, C.A. Miller, P.R. Garrett, K.H. Raney, J. Surf. Deterg. 8 (2005) 99-105.

[17] C.A. Miller, Curr. Opin. Colloid Interface Sci. 13 (2008) 177-182.

[18] H. Li, C. Yu, R.i Chen, J. Li, J. Li, Colloids Surf. A, 395 (2012) 116-121. 